\title{
Climate forcings and climate sensitivities diagnosed from atmospheric global circulation models
}

\author{
Bruce T. Anderson · Jeff R. Knight • \\ Mark A. Ringer - Clara Deser • Adam S. Phillips • \\ Jin-Ho Yoon · Annalisa Cherchi
}

Received: 30 March 2009/ Accepted: 15 March 2010/Published online: 31 March 2010

(C) Springer-Verlag 2010

\begin{abstract}
Understanding the historical and future response of the global climate system to anthropogenic emissions of radiatively active atmospheric constituents has become a timely and compelling concern. At present, however, there are uncertainties in: the total radiative forcing associated with changes in the chemical composition of the atmosphere; the effective forcing applied to the climate system resulting from a (temporary) reduction via ocean-heat uptake; and the strength of the climate feedbacks that subsequently modify this forcing. Here a set of analyses derived from atmospheric general circulation model simulations are used to estimate the effective and total radiative forcing of the observed climate system due to anthropogenic emissions over the last 50 years of the twentieth century. They are also used to estimate the sensitivity of the observed climate system to these emissions, as well as the expected change in
\end{abstract}

B. T. Anderson $(\varangle)$

Department of Geography and Environment,

Boston University, Boston, MA 02215, USA

e-mail: brucea@bu.edu

J. R. Knight · M. A. Ringer

Met Office Hadley Centre, Exeter EX1 3PB, UK

C. Deser · A. S. Phillips

National Center for Atmospheric Research,

Boulder, CO 80307, USA

J.-H. Yoon

Cooperative Institute for Climate and Satellites, Earth System

Science Interdisciplinary Center, University of Maryland,

College Park, MD 20742, USA

\section{A. Cherchi}

Centro Euro-Mediterraneo per i Cambiamenti Climatici, and Istituto Nazionale di Geofisica e Vulcanologia, Bologna, Italy global surface temperatures once the climate system returns to radiative equilibrium. Results indicate that estimates of the effective radiative forcing and total radiative forcing associated with historical anthropogenic emissions differ across models. In addition estimates of the historical sensitivity of the climate to these emissions differ across models. However, results suggest that the variations in climate sensitivity and total climate forcing are not independent, and that the two vary inversely with respect to one another. As such, expected equilibrium temperature changes, which are given by the product of the total radiative forcing and the climate sensitivity, are relatively constant between models, particularly in comparison to results in which the total radiative forcing is assumed constant. Implications of these results for projected future climate forcings and subsequent responses are also discussed.

\section{Introduction}

While the complexity of the fully coupled Earth system introduces numerous sources of uncertainty in its response to historical and future global climate-change influences, three stand out with respect to anthropogenically induced changes in global-mean surface temperatures: (1) the radiative forcing associated with changing concentrations of atmospheric chemical constituents; (2) the rate of ocean heat uptake and associated lag in the response of the climate system to this radiative forcing; and (3) the response of the climate system itself to this radiative forcing, vis a vis feedbacks within various Earth subsystems (e.g. Stott and Kettleborough 2002). Here we briefly describe each.

Recent analyses of coupled-climate model simulations suggest that the climate forcing associated with increased anthropogenic emissions of greenhouse gases and aerosols 
may differ between models (Collins et al. 2006). Much of this uncertainty is related to the influence that historical and future aerosol concentrations have upon the global climate system (Schwartz 2004), which arises from uncertainties in their impact on the reflection (Penner et al. 1994; Boucher et al. 1998) and absorption (Ramanathan and Carmichael 2008) of incoming solar radiation, as well as the indirect effects of aerosols upon cloud characteristics (Knutti et al. 2002; Quaas et al. 2006; Lohmann et al. 2007). More recently, however, it has been suggested that there also exist uncertainties in the direct forcing of the climate system associated with increasing concentrations of $\mathrm{CO}_{2}$ and other greenhouse gases, even for the same prescribed changes in radiatively active emissions/concentrations (Forster and Taylor 2006; Collins et al. 2006; IPCC 2007).

In addition, how this radiative forcing is partitioned between an effective radiative heating term which produces concurrent changes in the climate system, and ocean-heat uptake which results in a time-lag within the climate system to changes in the chemical composition of the atmosphere, depends upon ocean dynamics and thermodynamics (for instance related to the mixed-layer depth, diffusion rates, and mixing to the deeper ocean: Sokolov et al. 2003). While uncertainties in estimates of the observed ocean heat content over the course of the last century contribute to uncertainty in the effective heat capacity of the global Earth system and hence its response time to any applied forcing (Forest et al. 2002; Schwartz 2007; Knutti et al. 2008), research also suggests that these uncertainties tend to be small compared with uncertainties in the applied forcing over this time and in the climate response to this forcing (Wigley et al. 2005; Collins et al. 2007; Knutti and Tomassini 2008; Dufresne and Bony 2008).

Finally, it is well known that the climate response to changes in radiatively active atmospheric constituentstypically measured by the change in globally averaged surface temperatures and usually referred to as the climate sensitivity - is highly variable across model systems (IPCC 2007; Roe and Baker 2007). It is difficult to deduce these estimates from either short-term (Frame et al. 2005; Annan and Hargreaves 2006) or long-term (Hegerl 2006; Edwards et al. 2007) observational products. In addition, intermediate-complexity (Knutti et al. 2002) and fully coupled (Murphy et al. 2004; Soden and Held 2006; Sanderson et al., 2008) numerical model simulations also give wide ranges of uncertainty in how the global climate system may respond to a given forcing factor.

As discussed, much of the previous research into these uncertainties, particularly with regard to the sensitivity of the global climate system to imposed radiative forcing, has been based on the analysis of available observations (e.g. Annan and Hargreaves 2006) or projections from fully coupled numerical model simulations (e.g. Murphy et al. 2004). Alternatively, atmosphere-only general circulation models (AGCM) can also be used to estimate the sensitivity of the climate system by prescribing the climate change via the sea-surface temperatures (SSTs) and then using the top-of-atmosphere (TOA) radiative fluxes to deduce the necessary forcing needed to balance the imposed climate change (e.g. Cess et al. 1990; Ringer et al. 2006). This method has the advantage that it tests the sensitivity of the atmospheric and land-surface components of the climate system while ignoring (both numerically and physically) the details of the ocean system. In particular, these AGCMs overcome the problems associated with underestimation of natural (or internal) coupled ocean/ atmosphere variability because the sea-surface temperature evolution is specified from observations (Folland et al. 1998; Sexton et al. 2001). One disadvantage however is that they assume an equilibrium between the forcing of the climate system and the radiative response (see Cess et al. 1990, Eq. 1). In this sense, this method does not account for the time-lag arising from a radiative imbalance within the Earth's climate system associated with increased ocean heat content (Levitus et al. 2005; Hansen et al. 2005; Wong et al. 2006).

Here, we will use the Cess et al. (1990) methodology to estimate the historical climate sensitivity of the observed system to the effective radiative forcing over the last 50 years of the twentieth century. At the same time, we will utilize a modified version of the methodology that allows the atmospheric general circulation models to account for historical ocean heat uptake over the same time period and hence provide estimates of the historical evolution of the full radiative forcing fields as well. We will then compare the model estimates of climate sensitivity with estimates of full radiative forcing and show that the two are not independent, in agreement with previous findings (Web et al. 2006; Kiehl 2007; Knutti 2008). This result has important implications for the range of projections of climate variability associated with future anthropogenic emissions of greenhouse gases and aerosols.

\section{Data}

For this study, we will use output from AGCM simulations produced from the Community Atmosphere Model (CAM3.0-Collins et al. 2006); the Hadley Centre atmospheric model (HadAM3-Pope et al. 2000); the atmospheric component of the Coupled-AtmosphereBiosphere-Ocean model (CABO-Zeng et al. 2004); and the Euro-Mediterranean Centre for Climate Change model (CMCC), which is based upon the ECHAM4 AGCM 
(Roeckner et al. 1996). For the CAM3, CABO and CMCC models, two scenarios are considered. In the first, multiple simulations $(5,6$, and 5 , respectively) of the AGCM are forced only by historical changes in global SSTs (termed the AMIP simulation). In the second scenario, multiple simulations (again, 5, 6, and 5, respectively) are forced by historical changes in global SSTs, along with Greenhouse gas (GHG) concentrations, sulfate aerosols, volcanic particulates (CAM3 and CABO only), stratospheric and tropospheric ozone, and solar activity (termed the AMIPATM simulation). For the HadAM3 model, two scenarios are considered as well. In the first, five simulations of the AGCM are forced by historical changes in global SSTs as well as volcanic particulates and solar activity. These runs will be referred to as AMIP simulations with the understanding that they also include certain natural radiative forcings. In the second, five simulations are forced by historical changes in global SSTs, volcanic particulates, and solar activity, as well as GHG concentrations, sulfate aerosols, and stratospheric and tropospheric ozone (again, termed the AMIP-ATM simulation). For all the experiments we examine the period from 1950 to 1999 . Table 1 provides a summary description of the atmosphere-only model simulations used in the study.

To characterize changes in the overall planetary energy balance, this study will principally analyze top of atmosphere (TOA) outgoing longwave radiation (OLR) and net solar radiation (incoming minus outgoing). In addition we will analyze the simulated global near-surface temperature fields from the four models and two experimental set-ups. For comparison, observational estimates of global nearsurface temperatures are taken from the Hadley Centre's Climate Research Unit (CRU) gridded combined land/ marine data product (Jones et al. 1999; Brohan et al. 2006). All values presented here represent ensemble-mean, globally averaged estimates with a 12-month running-mean time-filter applied.

\section{Methods}

Previously, Cess et al. (1990) deduced the radiative forcing, $\Delta Q_{\text {tot }}$, needed to produce a given climate change by imposing changes in SSTs within an AGCM and then examining the resulting change in TOA net radiative fluxes, $\Delta R_{\mathrm{AMIP}}^{\mathrm{TOA}}$. In these simulations, the model is provided with no information about the forcing of the climate system, only the observed response of the climate to that forcing (as determined by the change in SST fields). The change in TOA net radiative fluxes then provides an estimate of the radiative forcing needed to produce the (imposed) climate change, $\Delta Q_{\mathrm{tot}}$, such that $\Delta Q_{\mathrm{tot}}=$ $-\Delta R_{\text {AMIP }}^{\text {TOA }}$ (e.g. Cess et al. 1990; Ringer et al. 2006).

However, their study assumes that the ocean state is in equilibrium with the radiative forcing itself. As evidenced from recent analyses of observations (Levitus et al. 2005), coupled-climate model simulations (Hansen et al. 2005), and remotely sensed data (Wong et al. 2006), there has

Table 1 Name and characteristics of model simulations used in this analysis

\begin{tabular}{|c|c|c|c|c|}
\hline Name & Resolution & Forcing & Duration & \# in ensemble \\
\hline CAM3.0 AMIP & T85 (about $1.4^{\circ}$ ) & SSTs & $1950-2000$ & 5 \\
\hline CABO AMIP & Latitude-Longitude: $5.625^{\circ} \times 3.75^{\circ}$ & & & 6 \\
\hline CMCC AMIP & T42 (about $2.8^{\circ}$ ) & & & 5 \\
\hline CAM3.0 AMIP-ATM & T85 (about $1.4^{\circ}$ ) & SSTs & 1950-2000 & 5 \\
\hline CABO AMIP-ATM & Latitude-Longitude: $5.625^{\circ} \times 3.75^{\circ}$ & GHGs & & 6 \\
\hline \multirow[t]{4}{*}{ CMCC AMIP-ATM } & T42 (about $2.8^{\circ}$ ) & Sulfate aerosols & & 5 \\
\hline & & Volcanic particulates (CAM3.0, CABO) & & \\
\hline & & Ozone & & \\
\hline & & Solar activity & & \\
\hline \multirow[t]{3}{*}{ HadAM3 AMIP } & Latitude-Longitude: $3.75^{\circ} \times 2.5^{\circ}$ & SSTs & $1950-2000$ & 5 \\
\hline & & Volcanic particulates & & \\
\hline & & Solar activity & & \\
\hline \multirow[t]{6}{*}{ HadAM3 AMIP-ATM } & Latitude-Longitude: $3.75^{\circ} \times 2.5^{\circ}$ & SSTs & 1950-2000 & 5 \\
\hline & & GHGs & & \\
\hline & & Sulfate aerosols & & \\
\hline & & Volcanic particulates & & \\
\hline & & Ozone & & \\
\hline & & Solar activity & & \\
\hline
\end{tabular}


been an increase in the heat content of the ocean arising from a radiative imbalance within the Earth's climate system. These results suggest that the full anthropogenic radiative forcing applied over the last $50+$ years, $\Delta Q_{\mathrm{tot}}$, is being partitioned between an effective radiative heating term, $\Delta Q_{\text {eff }}$, and ocean-heat uptake, $\Delta Q_{\text {ocn }}$ (Sokolov et al. 2003):

$\Delta Q_{\mathrm{tot}}=\Delta Q_{\mathrm{eff}}+\Delta Q_{\mathrm{ocn}}$.

In this case, the historical changes in SSTs are assumed to be responding to the effective radiative forcing, $\Delta Q_{\text {eff }}$, not the full radiative forcing. Hence, we modify the Cess et al. (1990) methodology by replacing $\Delta Q_{\text {tot }}$ with $\Delta Q_{\text {eff }}$. The relation between $\Delta R_{\mathrm{AMIP}}^{\mathrm{TOA}}$ and $\Delta Q_{\mathrm{eff}}$ then becomes:

$\Delta Q_{\mathrm{eff}}=-\Delta R_{\mathrm{AMIP}}^{\mathrm{TOA}}$.

In comparison, when an AGCM is run with explicit changes in both SSTs and atmospheric chemical constituents, the model is provided with information about both the forcing of the climate system (as determined by the historical evolution of radiatively active chemical constituents) as well as the observed response of the climate to that forcing (as determined by the historical evolution of the SST fields). Hence, the change in TOA radiation $\left(\Delta R_{\mathrm{AMIP}-\mathrm{ATM}}^{\mathrm{TOA}}\right)$ represents the sum of the explicitly imposed radiative forcing $\left(\Delta Q_{\text {tot }}\right)$ and the imposed SST forcing (given by $\left[-\Delta Q_{\text {eff }}\right]$ ). As discussed in Hansen et al. (2002) (and as is evident from Eqs. 1, 2), this sum represents the ocean-heat uptake of the full radiative forcing:

$\Delta R_{\mathrm{AMIP}-\mathrm{ATM}}^{\mathrm{TOA}}=\Delta Q_{\mathrm{tot}}+\left(-\Delta Q_{\mathrm{eff}}\right)=\Delta Q_{\mathrm{tot}}-\Delta Q_{\mathrm{eff}}$

$$
=\Delta Q_{\mathrm{ocn}} \text {. }
$$

From this equation, we also see that $\Delta R_{\mathrm{AMIP}-\mathrm{ATM}}^{\mathrm{TOA}}$ represents the difference between the explicitly imposed radiative forcing associated with changing chemical constituents $\left(\Delta Q_{\mathrm{tot}}\right)$ and the effective radiative forcing needed to produce the historical evolution of SSTs ( $\left.\Delta Q_{\text {eff }}\right)$. Hence, an estimate of the total forcing of the climate system can be derived by taking the difference between the TOA net radiative-flux terms from the two AGCM simulations:

$\Delta R_{\mathrm{AMIP}-\mathrm{ATM}}^{\mathrm{TOA}}-\Delta R_{\mathrm{AMIP}}^{\mathrm{TOA}}=\Delta Q_{\mathrm{ocn}}-\left(-\Delta Q_{\mathrm{eff}}\right)=\Delta Q_{\mathrm{tot}}$

Another way to arrive at this equation is to consider the difference of the two simulations as a modification of the archetypical "cloud radiative forcing" methodology (Cess et al. 1990). In that setting, the net incoming TOA radiation for cloudy conditions is compared with that from clear conditions; the imbalance gives the radiative forcing imparted by the clouds. In the case presented here, the
AMIP simulation can be considered the "clear" conditions in which no changes in radiatively active chemical constituents are introduced; analogously, the AMIP-ATM simulation can be considered the "cloudy" conditions in which a radiatively active profile is introduced. The difference between AMIP-ATM net incoming TOA radiation and the AMIP net incoming TOA radiation then gives the radiative forcing associated with changes in the radiatively active chemical composition of the atmosphere, i.e. $\Delta Q_{\mathrm{tot}}=\Delta R_{\mathrm{AMIP}-\mathrm{ATM}}^{\mathrm{TOA}}-\Delta R_{\mathrm{AMIP}}^{\mathrm{TOA}}$.

These relationships are confirmed by taking the difference between $\Delta R_{\mathrm{AMIP}-\mathrm{ATM}}^{\mathrm{TOA}}$ and $\Delta R_{\mathrm{AMIP}}^{\mathrm{TOA}}$, and comparing it with globally averaged TOA net radiative fluxes from a model that is forced only by historical changes in GHG concentrations, sulfate aerosols, volcanic particulates, stratospheric and tropospheric ozone, and solar activity, while keeping the sea-surface temperatures at their climatological values (termed the ATM simulation). These globally averaged TOA net radiative fluxes, $\Delta R_{\mathrm{ATM}}^{\mathrm{TOA}}$, provide a direct estimate of the explicitly imposed radiative forcing, $\Delta Q_{\mathrm{tot}}$, associated with changing chemical constituents (Hansen et al. 2002; Shine et al. 2003; Gregory and Webb 2008). Figure 1 shows that the direct estimates of $\Delta Q_{\mathrm{tot}}=\Delta R_{\mathrm{ATM}}^{\mathrm{TOA}}$ from the CAM3.0 model match the indirect estimates derived by taking the difference between $\Delta R_{\mathrm{AMIP}-\mathrm{ATM}}^{\mathrm{TOA}}$ and $\Delta R_{\mathrm{AMIP}}^{\mathrm{TOA}}$ values.

When estimated in this manner, the total radiative forcing accounts for the adjustment of the stratosphere and troposphere and is sometimes referred to as "fixed sea surface temperature forcing" (Hansen et al. 2002). It should be noted, however, that this experiment differs from that of Shine et al. (2003), in which both the SSTs and land-surface temperatures (LST) are prescribed. In those experiments it was found that the magnitude of radiative forcing estimated from the ATM-type GCM experiments is too high if only SSTs are prescribed. However, Shine et al. (2003) found that this excess forcing was most pronounced for processes affecting the shortwave component of the Earth's radiation budget (either due to solar or aerosol effects); the estimates for forcing associated with increasing GHGs were identical. In addition, Fig. 1b suggests that the total radiative forcing estimated directly from the ATM simulations (in which the excess forcing is present) is nearly identical to that estimated from the AMIP and AMIP-ATM simulations (in which the excess forcing cancels itself), suggesting that any net excess forcing associated with solar (positive) and aerosol (negative) effects may in fact be small for these historical simulations.

Based upon these results, and the above theoretical considerations, we will now use AGCM-only simulations-incorporating SST-only and SST and radiatively active atmospheric forcing-to estimate the historical 
Fig. 1 a Change in globally averaged net incoming top of atmosphere (TOA) radiation $\left(\mathrm{W} \mathrm{m}^{-2}\right.$ ) from the ensemble mean CAM3.0 AMIP (blue), AMIP-ATM (red), and ATM (black) simulations. Time-series are smoothed using a 12-month box-filter and plotted such that the 5-year period at the beginning of the time-series is centered on 0 . b Change in historical radiative forcing, $\Delta R_{\text {tot }}$, as derived from the difference between the globally averaged net incoming TOA radiation from the CAM 3.0 AMIP-ATM and AMIP simulations (blue), and from the CAM3.0 ATM simulations (black)

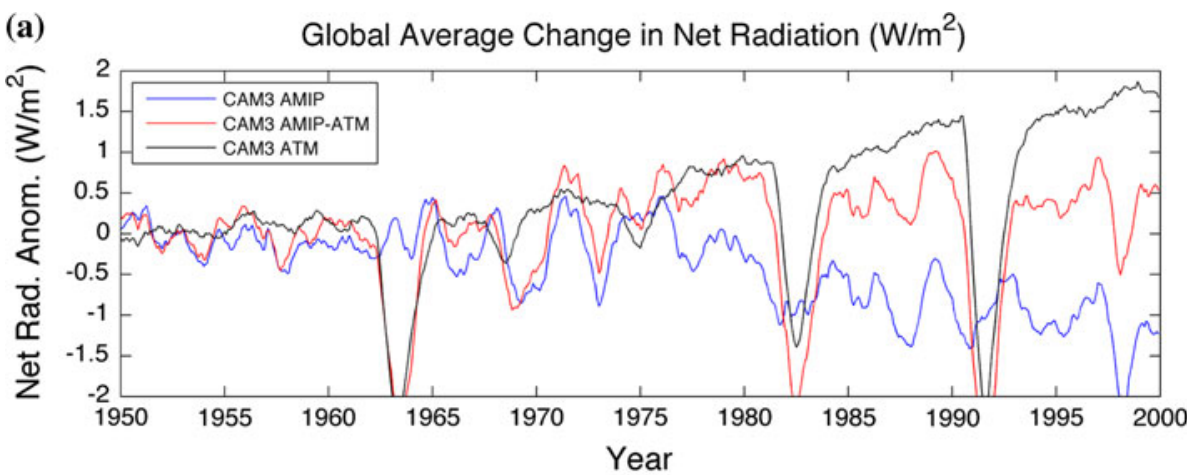

(b) Difference in Global Average Change in Net Radiation $\left(\mathrm{W} / \mathrm{m}^{2}\right)$

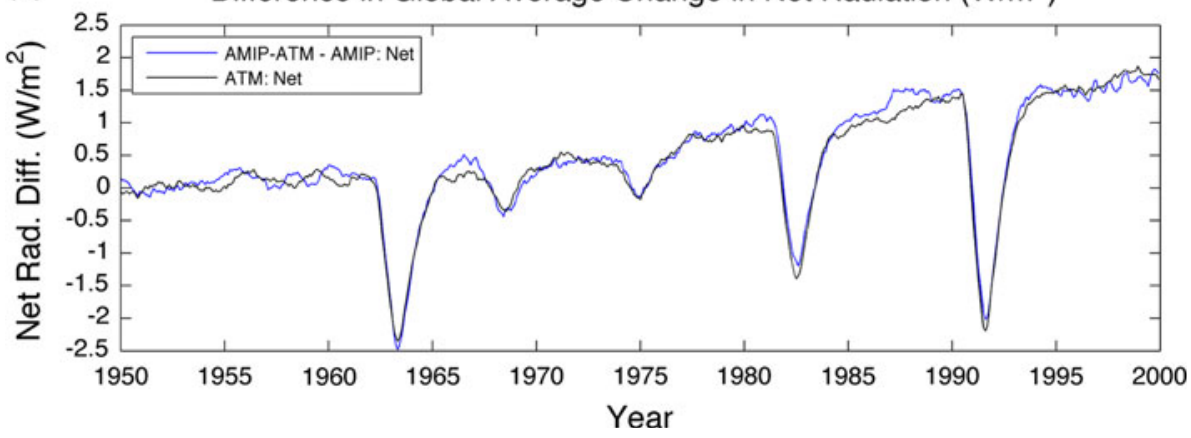

effective radiative forcing, total radiative forcing, and climate sensitivities for various atmospheric modeling systems.

\section{AGCM results}

Figure 2 shows the global-average surface temperatures taken from the CRU observational product, along with the AGCMs. Global temperature changes in both the AMIP and AMIP-ATM simulations approximate the observed global temperature changes, which is to be expected since the SST evolution is prescribed in these simulations (Compo and Sardeshmukh 2009). At the same time it is important to note that the atmosphere-only models are not explicitly "tuned" to match the observed surface temperature changes (although they may be implicitly tuned to reproduce observed climatological patterns of temperature and precipitation, for instance), which are instead to first order dictated by the historical changes in SSTs. Our interest here is in diagnosing the models' responses to these changing SSTs (and atmospheric chemical constituents).

Figure 3 shows the globally averaged net incoming TOA radiation from the ensemble-mean AMIP and AMIPATM simulations. The largest variations are associated with the volcanic eruptions of Agung (1963), El Chichon (1982), and Pinatubo (1991-Robock 2000). However, results also indicate that all four AMIP simulations, which do not contain explicit anthropogenic changes in the chemical composition of the atmosphere, produce a net loss of radiative energy through the top of the atmosphere associated with global-scale increases in SSTs (Cess et al. 1990; Trenberth et al. 2002). In contrast, for the AMIPATM simulations there is a long-term increase in the net incoming TOA radiation, indicating a net retention of energy within the earth system despite the increase in SST fields (Kiehl 1983; Goody et al. 1996; Mitchell et al. 1987; Harries et al. 2001; Brindley and Allan 2003). As mentioned above, the differences in the net TOA radiative flux fields from the two simulations gives the total radiative forcing, $\Delta Q_{\text {tot }}$ (Fig. 3b). This figure indicates that the four models contain variable estimates of the radiative forcing associated with the historical evolution of radiatively active chemical constituents. Part of this variability is due to the exclusion of certain chemical constituents (volcanic particulates) from the CAM3 and CABO AMIP simulations, which is manifested as significant decreases in the net radiation difference curves in the early 1960s, 1980s, and 1990s (again, associated with the eruptions of Agung, El Chichon, and Pinatubo, respectively). However, there are also inter-model variations in the long-term trends in the radiative forcing, which we investigate in more detail below.

To better analyze the changes in each model, Fig. 4 shows the overall trends in various surface and TOA fields, derived by taking the difference between the 5 -year mean values at the beginning and end of each integration; we 


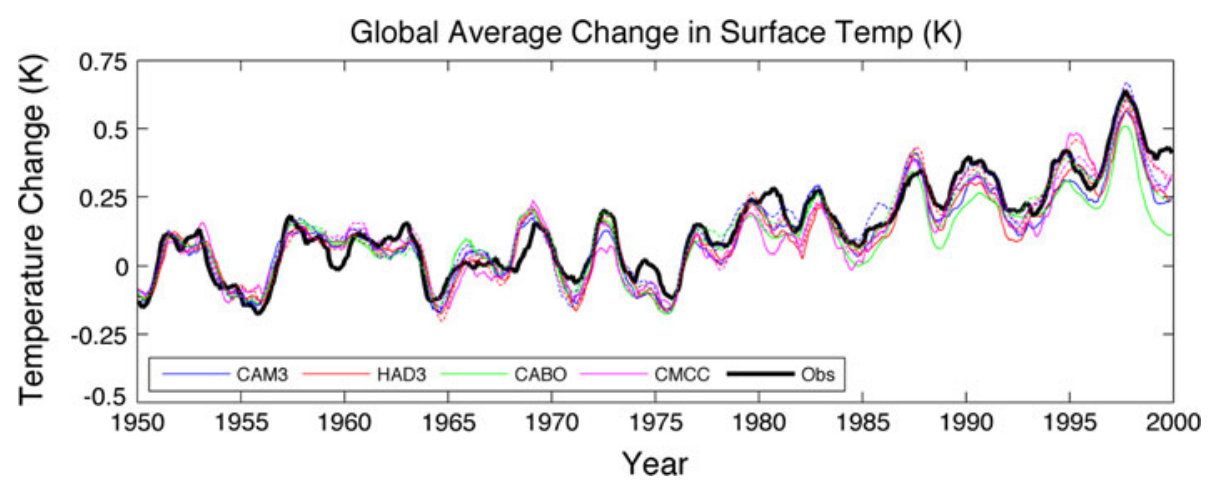

Fig. 2 Change in globally averaged surface temperatures (K) for the CAM3, HAD3, CABO and CMCC simulations (thin, colored lines) and the CRU observations (thick, black line). Solid (dashed) lines indicate surface temperatures derived from the AMIP (AMIP-ATM) simulations. Time-series are smoothed using a 12-month box filter and plotted such that the 5-year period at the beginning of the timeseries is centered on 0
Fig. 3 a Change in globally averaged net incoming top of atmosphere (TOA) radiation $\left(\mathrm{W} \mathrm{m}^{-2}\right.$ ) for the CAM3, HAD3, $\mathrm{CABO}$ and $\mathrm{CMCC}$ derived from AMIP (solid) and AMIP-ATM (dashed) simulations. Timeseries are smoothed using a 12-month box filter and plotted such that the 5-year period at the beginning of the time-series is centered on 0 . b Difference between the globally averaged net incoming TOA radiation from AMIP-ATM and AMIP simulations for the CAM3, HAD3, CABO and CMCC
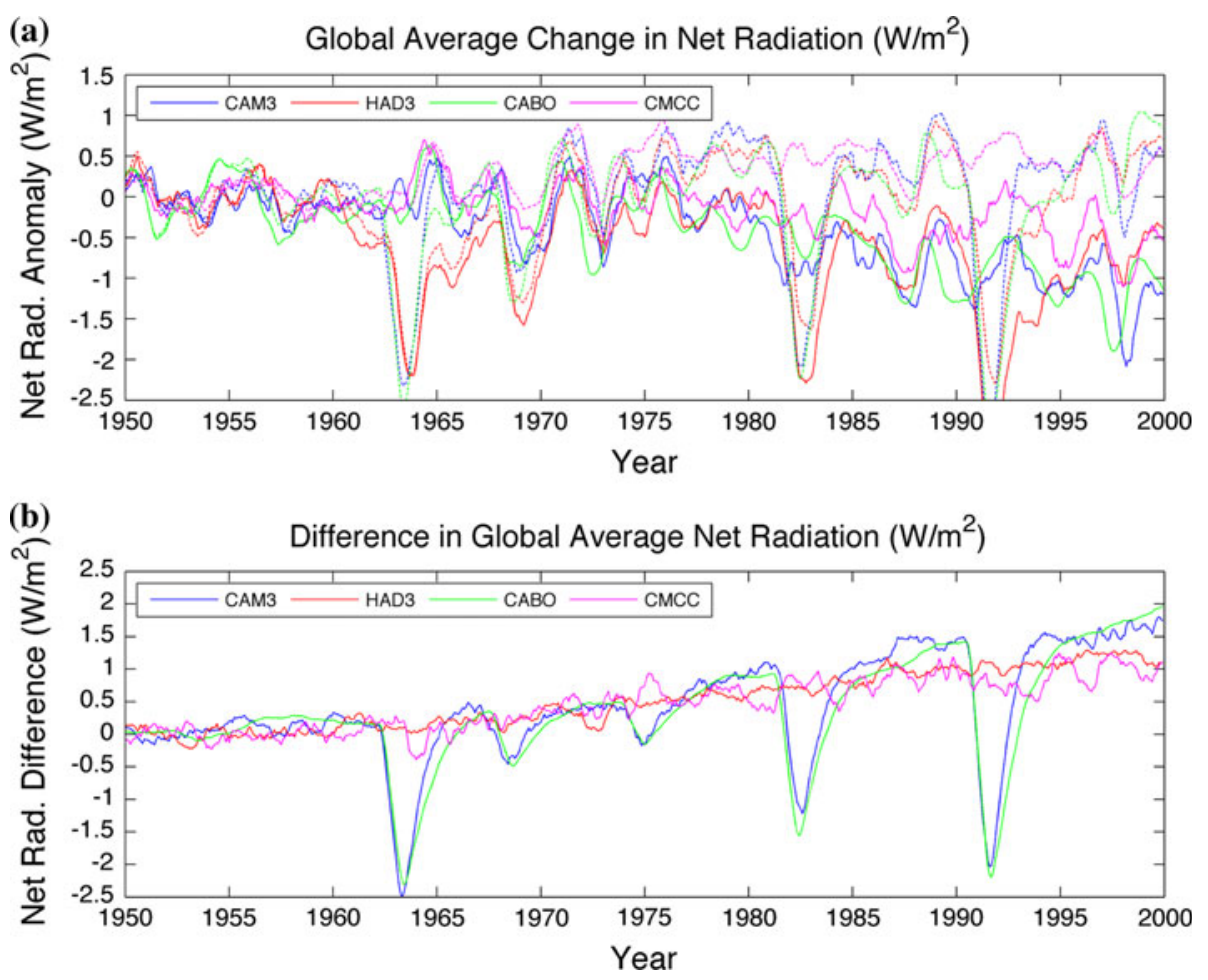

performed the analysis in this manner to avoid end-effects (associated with Pinatubo-related volcanic signatures near the end of the CAM3 and CABO simulations) that arose when applying simple linear trends across the entire timeseries. Figure 4 a shows the historical trends in global surface temperatures, both from the AMIP and AMIP-ATM simulations. The slightly larger global surface temperature changes found in the AMIP-ATM simulations compared with the AMIP simulations (except for CMCC) are related to climate changes that are forced directly by the inclusion of anthropogenic chemical constituents, separate from those that arise indirectly from the anthropogenic chemical constituents' impact upon SST and sea-ice changes
(Folland et al. 1998; Sexton et al. 2001). The ATM-AMIP global surface temperature trends generally have similar values across the models with an average of $0.41 \mathrm{~K}$; for the AMIP simulations the global surface temperature trends average $0.35 \mathrm{~K}$. The observed temperature change for this period, taken from the CRU data, is $0.43 \mathrm{~K}$.

Examining the trends in TOA radiation fields from the AMIP runs next (Fig. 4b), we find that the effective radiative forcing, $\Delta Q_{\mathrm{eff}}\left(=-\Delta R_{\mathrm{AMIP}}^{\mathrm{TOA}}\right)$, needed to produce the observed historical climate change over the last 50 years of the twentieth century differs in each model. These differences arise both because of differences in the longwave response, as well as the shortwave response (Cess et al. 
Fig. 4 a Trends in globally averaged surface temperatures (K) from the AMIP (blue) and AMIP-ATM (red) simulations from CAM3, HAD3, CABO and CMCC. b Trends in globally averaged incoming top of the atmosphere radiation (longwave in blue, shortwave in red, and net in green; $\mathrm{W} \mathrm{m}^{-2}$ ) from the AMIP simulations for CAM3, HAD3, CABO and CMCC. Positive values indicate increases in downward radiation. c Same as b except for AMIP-ATM simulations. d Same as b except for difference between AMIP-ATM and ATM simulations
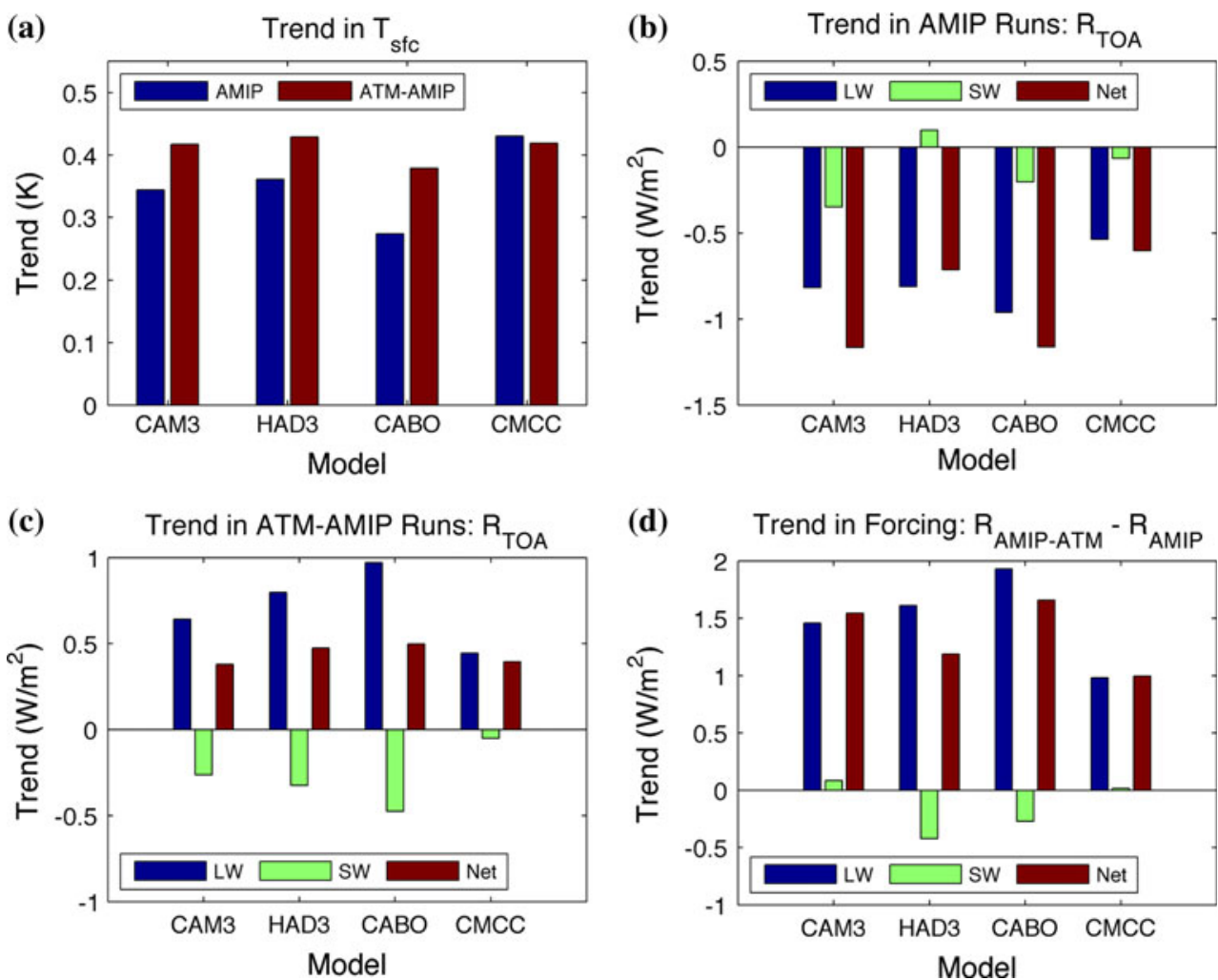

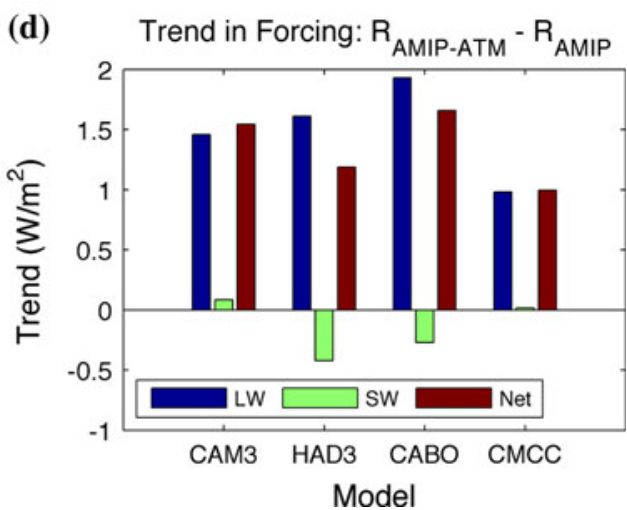

1990; Ringer et al. 2006), and differ by a factor of two (from 0.6 to $1.16 \mathrm{~W} \mathrm{~m}^{-2}$ ). If we examine the trends in TOA radiation fields from the AMIP-ATM runs (Fig. 4c), we find that there are still inter-model differences in both the longwave and shortwave trends. However, as with the surface temperature estimates, the net trends are fairly similar in all four models $\left(0.38-0.50 \mathrm{~W} \mathrm{~m}^{-2}\right)$. As before, the changes in TOA radiation $\left(\Delta R_{\mathrm{AMIP}-\mathrm{ATM}}^{\mathrm{TOA}}\right)$ from these models give an estimate of the associated energy fluxes from the atmosphere to the underlying surface (predominantly the ocean surface, and to a lesser extent the land surface: Levitus et al. 2005) over the course of the simulation, represented by $\Delta Q_{\text {ocn }}$.

As suggested above, if we take the difference between the TOA radiation from the AMIP-ATM $\left(\Delta R_{\mathrm{AMIP}-\mathrm{ATM}}^{\mathrm{TOA}}\right)$ and the AMIP $\left(\Delta R_{\mathrm{AMIP}}^{\mathrm{TOA}}\right)$ simulations, we arrive at an estimate of the total radiative forcing associated with changing anthropogenic chemical constituents $\left(\Delta Q_{\text {tot }}\right.$ Fig. 4d). As suggested by the time-evolution of these estimates in Fig. 2b, the overall trend of the total historical radiative forcing over the 50-year period differs in each model, and ranges from 1.00 to $1.67 \mathrm{~W} \mathrm{~m}^{-2}$ or a factor of two-thirds. In addition, the longwave and shortwave components of this forcing also differ (ranging from 0.98 to 1.93 and -0.42 to $0.09 \mathrm{~W} \mathrm{~m}^{-2}$ respectively). These results agree with those of Forster and Taylor (2006), which indicate that a factor of two difference can be found in the longwave forcing of coupled-climate models, even given the same future changes in GHG concentrations.

From these results we find that both the effective radiative forcing and total radiative forcing within each model seem to differ (see Fig. 4b, d). Plotting the two against one another (Fig. 5a), we find that there is a nearly uniform offset between the effective radiative forcing and total radiative forcing within each model. Fitting these data points with a linear trend, $\Delta Q_{\text {tot }}=\alpha \Delta Q_{\text {eff }}+\beta$, we find that $\alpha=1.02$ and $\beta=0.42 \mathrm{~W} \mathrm{~m}^{-2}$. The offset value, $\beta$, is nearly equivalent to the mean estimated ocean-heat uptake found in Fig. $4 \mathrm{c}\left(\Delta Q_{\mathrm{ocn}}=0.44 \mathrm{~W} \mathrm{~m}^{-2}\right)$, as expected.

Given estimates of the change in effective radiative forcing from the AMIP simulations and the associated global temperature change, we can derive an estimate of the sensitivity, $\lambda$, for each of the AGCMs, defined here as $\lambda=\Delta T_{\text {eff }} / \Delta Q_{\text {eff }}$ (Cess et al. 1990), where $\Delta T_{\text {eff }}$ is the effective (i.e. realized) global temperature change over the course of the simulation period. If we then plot the model sensitivities against the total radiative forcing estimates, we find an inverse relation between the two (Fig. 5b). This result suggests that a given atmospheric model's radiative response to imposed radiatively active chemical constituents (i.e. the total radiative forcing) is inversely related to the model's internal climate sensitivity. A similar inverse relation between climate-sensitivity and radiative forcing has been found in historical 


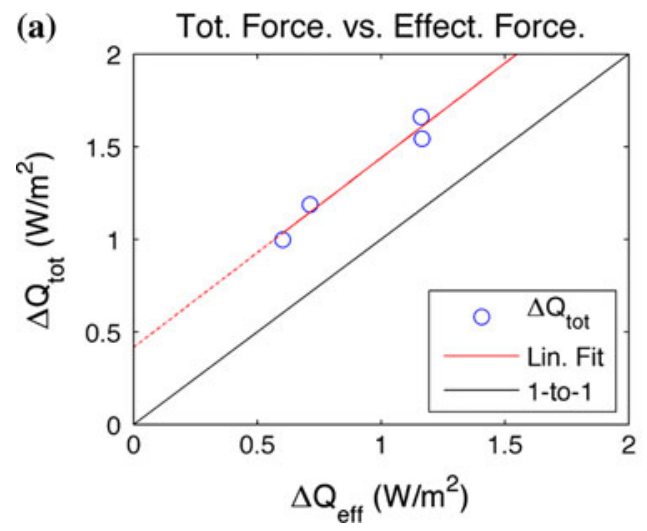

Fig. 5 a Effective radiative forcing $\left(\Delta Q_{\text {eff }}-\mathrm{W} \mathrm{m}{ }^{-2}\right)$ derived from trends in globally averaged incoming top of the atmosphere (TOA) radiation from the AMIP simulations, plotted against the total radiative forcing $\left(\Delta Q_{\mathrm{tot}}-\mathrm{W} \mathrm{m}{ }^{-2}\right)$ derived from the difference between trends in the AMIP-ATM and AMIP globally averaged incoming TOA radiation for the CAM3, HAD3, CABO and CMCC. Also shown are the one-to-one line (black) and a linear trend fitted to

coupled-climate model simulations of the twentieth century climate system (Kiehl 2007), which is attributed to the differences in aerosol forcings (i.e. changes in incoming absorbed shortwave radiation) imposed in different models. However, from the AGCM results it appears that there are also significant differences in the longwave radiative forcing component (see Fig. 4d); generally, the inter-model differences in total radiative forcing presented here are better correlated with the longwave radiative forcing component $(r=0.80)$ than they are with the shortwave radiative forcing component $(r=-0.03)$. We discuss the contributions of each component to the total radiative forcing further in Sect. 5.

Before going on, it is important to note that the apparent inverse relation between total radiative forcing and climate sensitivity within these AGCMs is not a consequence of the models using the same prescribed temperature evolution (via historical SSTs). Indeed, when the model comparison was first performed, it was expected that each of the AGCMs would have very similar estimates of total radiative forcing, which would be partitioned differently into effective heating (as determined from the AMIP simulations) and ocean-heat uptake (as determined from the AMIP-ATM simulations) by each model. Alternatively, each model could have provided independent estimates of effective radiative heating, ocean-heat uptake, and total radiative forcing, based upon the numerical specifics of each model itself. Instead, we find that the various estimates from each model are not independent and that in fact there are significant inter-model differences in total radiative forcing, which vary inversely with respect to their differences in climate sensitivity.

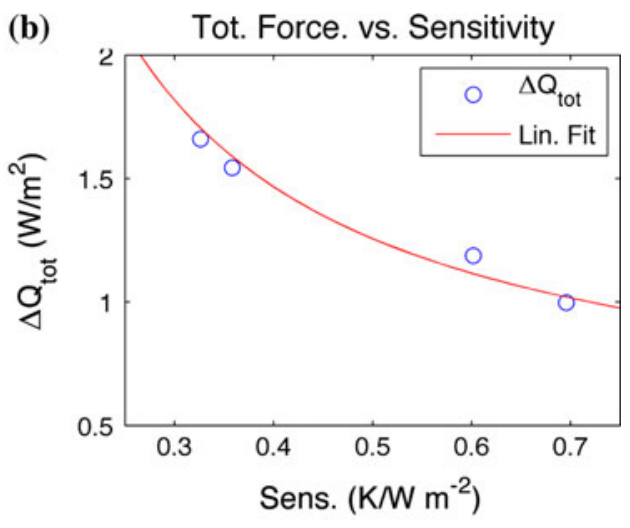

the individual model data (red). b Sensitivity of the AGCM, plotted against $\Delta Q_{\text {tot }}$ for the CAM3, HAD3, CABO and CMCC. Sensitivity calculated as the trend in globally averaged surface temperatures from the AMIP-ATM simulations, divided by $\Delta Q_{\text {eff. }}$ Also shown is the interpolated sensitivity derived from the linearly fitted total radiative forcing in a (red line)

Based upon these results, we can find the equilibrium temperature change- the temperature change expected for the present total radiative forcing once the system comes back into equilibrium - by taking the product of the sensitivity and the total radiative forcing from a given model (Fig. 6a). Because the total radiative forcing and sensitivity are inversely related to one another, the equilibrium temperatures across the models show a smaller range than would be expected if a fixed total radiative forcing was presumed (here set to the average total radiative forcing from the four models, $\sim 1.35 \mathrm{~W} \mathrm{~m}^{-2}$ ). Based upon the linear relation found earlier, we can derive the hypothetical relation between the equilibrium temperature and the model sensitivity:

$\Delta T_{\text {eq }}=\alpha \Delta T_{\text {eff }}+\beta \lambda$

where $\alpha, \beta$ are the same as above. Since $\alpha=1.02$ and $\beta=0.42 \mathrm{~W} \mathrm{~m}^{-2}<1$, we find that when accounting for the relation between the radiative forcing and climate sensitivity of a given model, the range of equilibrium temperatures is significantly less than if a fixed radiative forcing is assumed. This result is also shown in Fig. 6b, in which the estimated equilibrium temperature response from the models, based upon the model-specific total radiative forcing and climate sensitivity, is compared with the estimated equilibrium temperature response based only upon the model's climate sensitivity and a fixed total radiative forcing equal to the average total radiative forcing from the four models.

If we next assume that the longwave component of radiative forcing scales (approximately) linearly with changes in greenhouse gas concentrations, as represented 


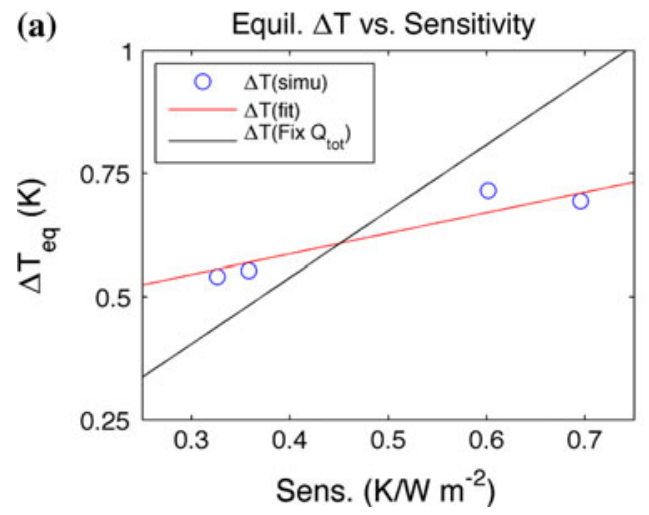

Fig. 6 a Sensitivity of the AGCM, plotted against the equilibrium temperature response of the AGCM $\left(\Delta T_{\mathrm{eq}}-\mathrm{K}\right)$ for the CAM3, HAD3, $\mathrm{CABO}$ and $\mathrm{CMCC}$. Equilibrium temperature response calculated as the product of the sensitivity and the total radiative forcing $\left(\Delta Q_{\mathrm{tot}}\right)$ of the AGCM. Also shown is the equilibrium temperature response assuming a fixed total radiative forcing equal to the mean of the four
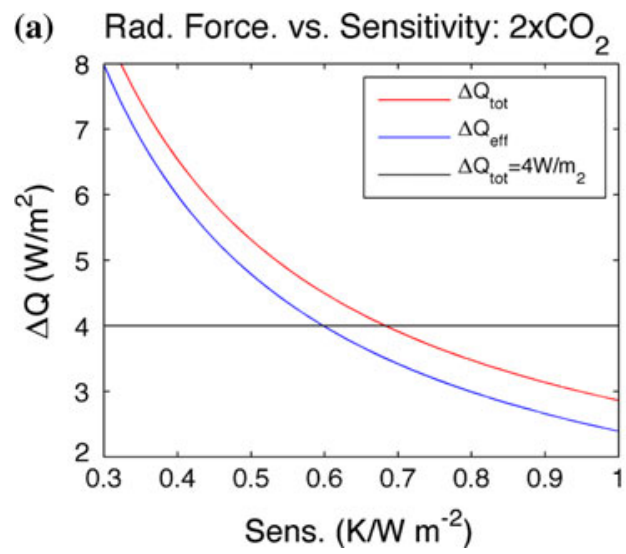

Fig. 7 a Total (red line) and effective (blue line) radiative forcing $\left(\mathrm{W} \mathrm{m}{ }^{-2}\right.$ ) associated with a doubling of pre-industrial $\mathrm{CO}_{2}$ concentrations, as derived from the linearly fitted total radiative forcing in Fig. 5a, scaled by the ratio of the future to historical changes in $\mathrm{CO}_{2}$ concentrations, relative to fixed total radiative forcing of $4 \mathrm{~W} \mathrm{~m}^{-2}$

by changes in $\mathrm{CO}_{2}$, we can estimate the relation between climate sensitivity and the total radiative forcing in response to a doubling of pre-industrial $\mathrm{CO}_{2}$ concentrations. This relation is shown in Fig. 7a. Here, the linearlyfitted total radiative forcing curve (seen in Fig. 5b) is scaled by the ratio of the changing concentrations associated with a doubling of $\mathrm{CO}_{2}$ (e.g. an increase of $280 \mathrm{ppm}$ ) to the historical changes during the period of investigation (which is approximately $58 \mathrm{ppm}$ over the time-period 1950-2000). If we then assume that the same linear relationship holds between effective radiative forcing and total radiative forcing, we can estimate the effective radiative forcing as well. Note that depending upon the model sensitivity, the total radiative forcing associated with a doubling of pre-industrial $\mathrm{CO}_{2}$ concentrations can be much

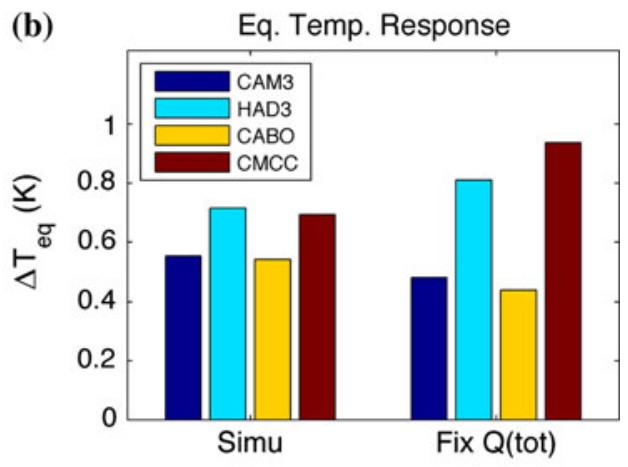

models (black line) and the interpolated equilibrium temperature response derived from the linearly fitted total radiative forcing in Fig. 5a (red line). b $\Delta T_{\mathrm{eq}}$ calculated as the product of the sensitivity and the globally averaged total radiative forcing of the AGCM (Simu) and as the product of the sensitivity and a fixed total radiative forcing equal to the mean of the four models [Fix $Q$ (tot)]

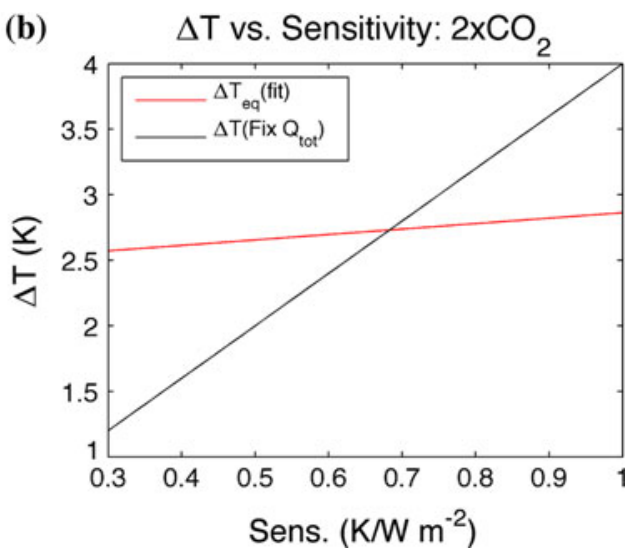

(black line). b Sensitivity of the AGCM, plotted against the equilibrium temperature response $\left(\Delta T_{\mathrm{eq}}-\mathrm{K}\right)$ for a doubling of preindustrial $\mathrm{CO}_{2}$ concentrations. Equilibrium temperature response calculated as the product of the sensitivity and the linearly fitted (fixed) total radiative forcing shown in red (black)

greater (or less) than the commonly assumed value of $4 \mathrm{~W} \mathrm{~m}^{-2}$.

We subsequently estimate the equilibrium temperature change associated with a doubling of pre-industrial $\mathrm{CO}_{2}$ concentrations, $\Delta T_{\mathrm{eq}}\left(2 x \mathrm{CO}_{2}\right)$, by taking the product of $\lambda$ and $\Delta Q_{\text {tot }}\left(2 x \mathrm{CO}_{2}\right)$ from above (Fig. $\left.7 \mathrm{~b}\right)$. We find that because of the inverse relation between climate sensitivity and total (and effective) radiative forcing, the overall range of estimated temperature changes is reduced compared with those found by assuming a fixed radiative forcing (equal to $4 \mathrm{~W} \mathrm{~m}^{-2}$ ) for all climate sensitivities. In the example here, the range, when accounting for the dependency of the total radiative forcing to the climate sensitivity, is $2.5-3 \mathrm{~K}$, compared with a range of $1.25-4 \mathrm{~K}$ when using fixed estimates of total radiative forcing. 


\section{Coupled climate model results}

In the previous section we discussed how AGCM-only simulations, incorporating SST-only and SST and radiatively active atmospheric forcing, can be used to estimate the historical effective radiative forcing, total radiative forcing, and climate sensitivities for various models. One of the more intriguing results is that the total (and effective) radiative forcing applied to the climate differs from one model to another, in agreement with independent coupled-climate model results (Forster and Taylor 2006; Collins et al. 2006; IPCC 2007). In addition, our results suggest that the strength of this total radiative forcing is a function of the internal climate sensitivity of the model itself, such that more sensitive climate models also impose less total radiative forcing.

To see whether this result is more generally applicable within coupled-climate model simulations (as suggested by Web et al. 2006; Kiehl 2007; Knutti 2008), we use the results from Forster and Taylor (2006), which compute the total radiative forcing and climate sensitivity (as represented by the inverse of the climate feedback term, $Y$ ) for 20 coupled-climate models forced solely by $1 \% /$ year increases in $\mathrm{CO}_{2}$ concentrations. Plotting the total radiative forcing against the model climate sensitivities (Fig. 8), we find that not all models have the same inverse relationship, as seen in the AGCM results. However, by plotting the assumed inverse relation that passes through each individual model estimate, we can see that two groups of models appear to have very similar radiative-forcing/climate-sensitivity relationships. If we also plot the equilibrium temperature response for each model, calculated as the product of the total radiative forcing and the climate sensitivity, we find that the models that have similar inverse relationships also have similar equilibrium temperature responses (to be expected since the individual curves are representative of all climate-forcing/climatesensitivity combinations that give the same equilibrium temperature response as the individual model value through which the curve passes). The partitioning between models with low, high, and outlying equilibrium temperature responses is confirmed by performing a K-means

Tot. Rad. Forcing vs. Sensitivity

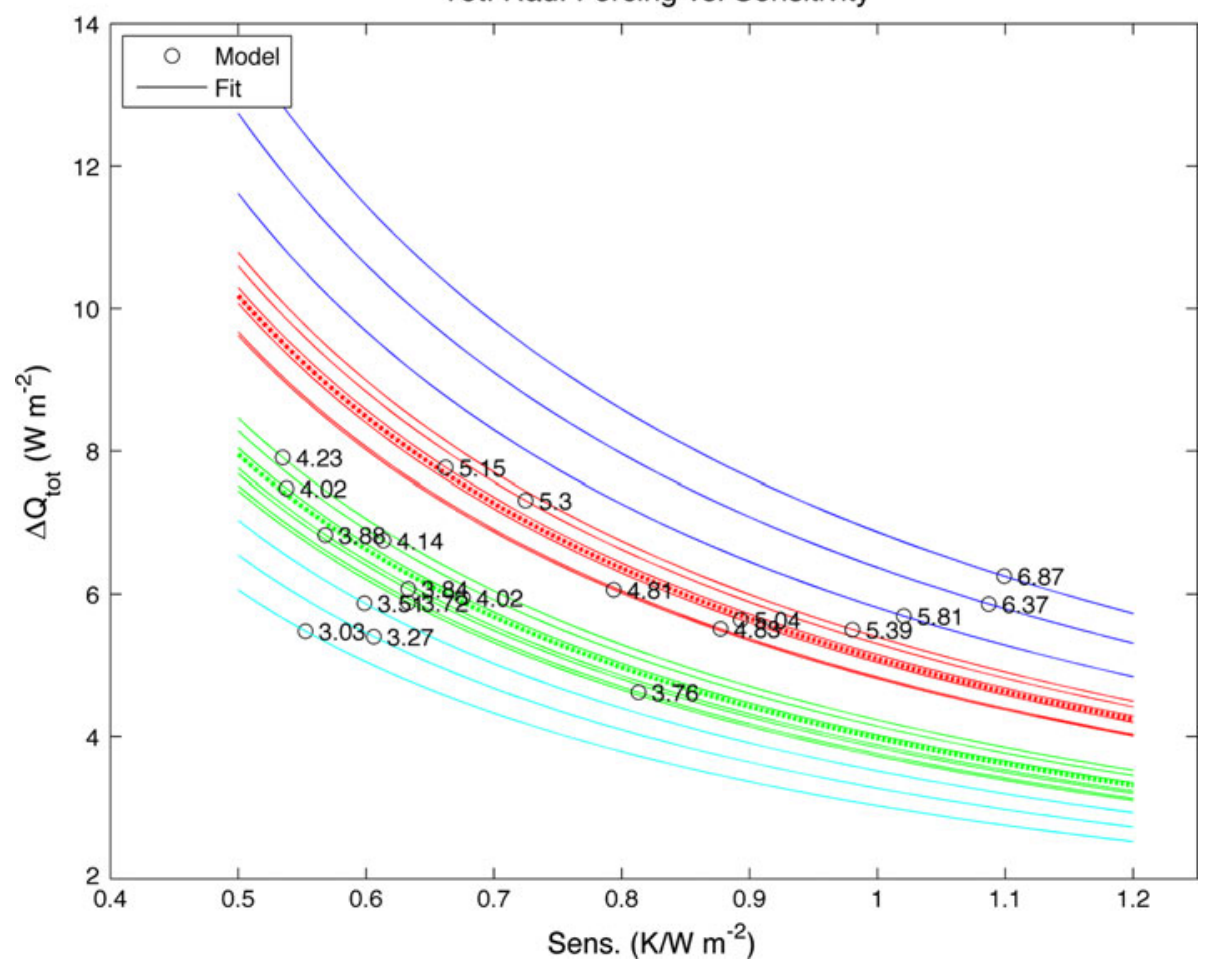

Fig. 8 Total radiative forcing $\left(\mathrm{W} \mathrm{m}^{-2}\right)$ associated with a $1 \% /$ year increase in $\mathrm{CO}_{2}$ concentrations for 20 coupled-climate models plotted against their respective climate sensitivities (black circles) from Forster and Taylor (2006) Table 3, along with the associated equilibrium temperature response $(\mathrm{K})$ estimated from the product of the total radiative forcing and climate sensitivity. Also shown is the radiative-forcing/climate-sensitivity curve (solid line) that passes through each coupled-climate model data point, assuming an inverse relation that maintains the same equilibrium temperature response. Two subsets of models are grouped together (green and red) based upon the similarity in their radiative-forcing/climate-sensitivity curves; outlier curves are shown in light/dark blue. Designations determined using a K-means clustering algorithm with four designated clusters, applied to the equilibrium temperature response from the 20 models-see text 
clustering (Gong and Richman, 1995) applied to the equilibrium temperature response from the 20 separate models. In addition, the selection of four clusters is confirmed by calculating the marginal improvement in unexplained variance between Cluster $n$ and Cluster $n+1$, which reaches a local minimum (and near-zero values) for $n \geq 4$, indicating that the inclusion of additional clusters provides little additional reduction in unexplained variance (not shown).

Figure 9 shows the individual model estimates of the equilibrium temperature response, plotted against the model's sensitivity. In addition, the plot shows the expected equilibrium temperature response if the total radiative forcing were the same in all models (and set equal to the mean of the 20 models, $\sim 6.2 \mathrm{~W} \mathrm{~m}^{-2}$ ). Those models that have very similar radiative-forcing/climate-sensitivity relationships show small variations in their estimated equilibrium temperature responses. At the same time, the presence of outlier models does suggest that the radiativeforcing/climate-sensitivity relationship is not robust across all models, raising the possibility of much greater (or smaller) equilibrium temperature responses to increasing concentrations of $\mathrm{CO}_{2}$ (which we discuss further below).

As mentioned, a similar inverse relation between climate sensitivity and historical radiative forcing has been found in coupled climate-model runs (Kiehl 2007). Previously, this inverse relation was attributed mainly to intermodel differences in the radiative forcing associated with historical increases in aerosols. Projections of future climate change incorporating this climate-sensitivity/climateforcing relation found that, unlike the results presented here, the inverse relation did not reduce uncertainties in future global temperature responses (Knutti 2008), mainly because the future longwave component to total radiative forcing (associated with future projections of greenhouse gas concentrations)—which was fixed across the model runs-overwhelms any future forcing associated with changing aerosol concentrations. However, from results presented above and in Forster and Taylor (2006), IPCC (2007), and Gregory and Webb (2008) it is emphasized that there are inter-model differences in the radiative forcing associated with increasing $\mathrm{CO}_{2}$ concentrations as well, and that these differences in radiative forcing may also have an inverse relation to a given model's climate sensitivity.

To further analyze why these inter-model differences in total radiative forcing arise, we plot the total radiative forcing estimates taken from Forster and Taylor (2006) against the longwave and shortwave radiative forcing estimates from the same study (Fig. 10). As before the models are segregated into those that have a low equilibrium temperature response, a high equilibrium temperature response, and those that have outlying equilibrium temperature responses. For the models that have similar low and high equilibrium temperature responses, it appears that there is a quasi-linear relation between the longwave and total radiative forcing estimates $(r=0.87$ and 0.89 ,
Fig. 9 Equilibrium temperature change $(\mathrm{K})$ associated with a $1 \%$ /year increase in $\mathrm{CO}_{2}$ concentrations for 20 coupledclimate models plotted against their respective climate sensitivities for low/high/outlier ( green/red/blue) equilibrium temperature groupings-see Fig. 8 for subsets of radiativeforcing/climate-sensitivity curves. Equilibrium temperature response calculated as the product of the sensitivity and the globally averaged total radiative forcing in Fig. 8. Also shown is equilibrium temperature response assuming a fixed total radiative forcing equal to the mean of the 20 coupled climate models ( $6.2 \mathrm{~W} \mathrm{~m}^{-2}$-black line $)$
Equil. $\Delta T$ vs. Sensitivity

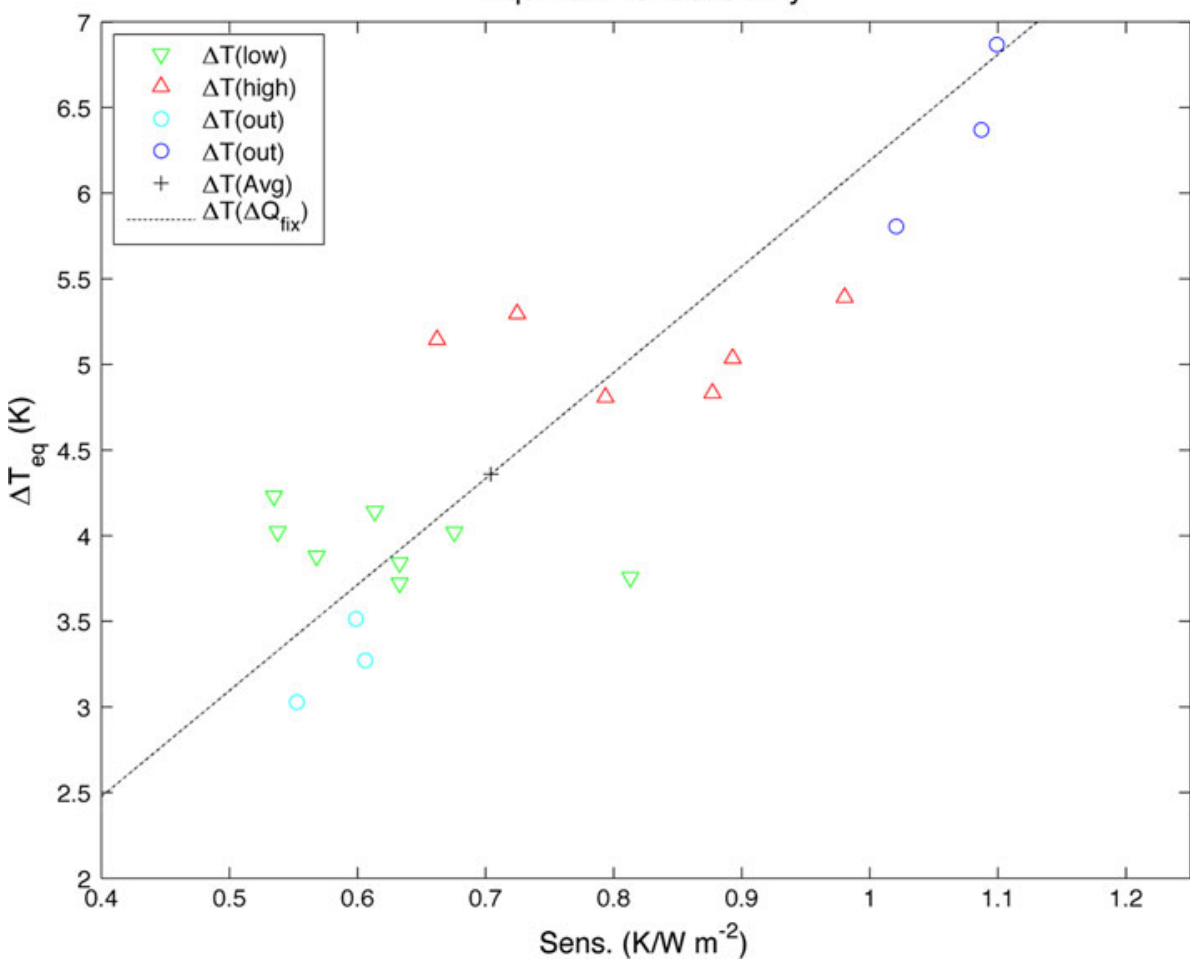




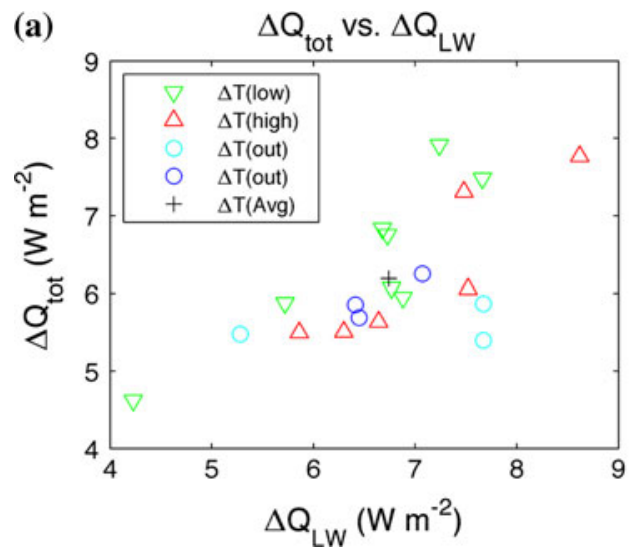

Fig. 10 a Total radiative forcing $\left(\mathrm{W} \mathrm{m}^{-2}\right)$ associated with a $1 \% /$ year increase in pre-industrial $\mathrm{CO}_{2}$ concentrations for 20 coupled-climate models plotted against their respective longwave radiative forcing component $\left(\mathrm{W} \mathrm{m}^{-2}\right)$ for low/high/outlier (green/red/blue)

respectively-Fig. 10a); however there is no similar relation between the shortwave and total radiative forcing estimates ( $r=0.20$ and 0.22 , respectively-Fig. 10b). These results suggest that the inverse relation between radiative forcing (both historical and future) and climate sensitivity may be associated with changing greenhouse gas concentrations as well as aerosols; as such this inverse relation may be more important for future climate change projections than is currently thought (e.g. Knutti 2008).

\section{Discussion}

One of the most important findings of the present analysis is an inverse relation between climate sensitivity and total radiative forcing within both historical AGCM simulations and forced coupled climate-model runs. This inverse relationship appears to be manifested in inter-model differences in the longwave component of the total radiative forcing. From the experiments we used and the analyses we performed, we construct the following hypothesis: Models that have enhanced longwave feedback processes-e.g. water vapor/lapse rate and/or cloud feedbacks (Bony et al., 2006) - by nature attenuate the transfer of outgoing longwave radiation more so than in models with less robust feedbacks. As such, in models with enhanced longwave feedbacks, the change in outgoing longwave radiation attributable to an increase in $\mathrm{CO}_{2}$ (and other greenhouse gases), above and beyond what is already being retained within the system by feedback processes, is expected to be less; e.g. the total radiative forcing attributable to the inclusion of additional $\mathrm{CO}_{2}$ in models with enhanced feedback processes is less than in those models with less robust feedbacks, as found here. Of course, it is still unclear which longwave feedback processes may be involved in

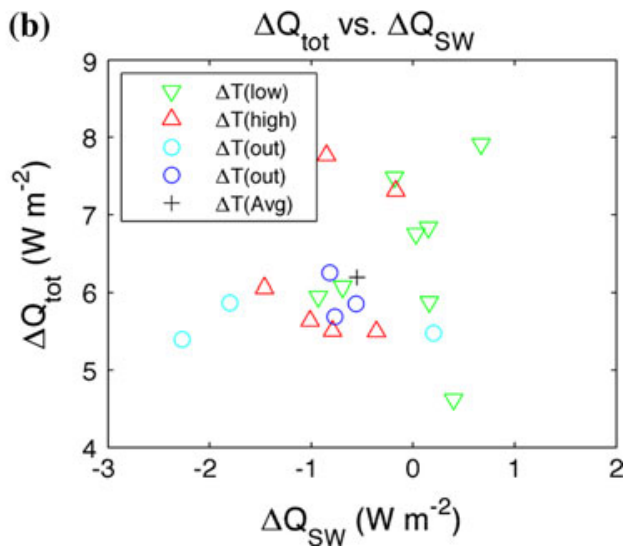

equilibrium temperature groupings-see Fig. 8 for subsets of radiative-forcing/climate-sensitivity curves. b Same as a except for the respective shortwave radiative forcing component

modifying the total radiative forcing associated with changes in the chemical composition of the atmosphere; in addition it is unclear whether the affected component of total radiative forcing is associated with instantaneous radiative forcing by $\mathrm{CO}_{2}$ or adjustments to the stratosphere, troposphere (Hansen et al. 2002; Shine et al. 2003) or possibly clouds (Gregory and Webb 2008).

An explicit test of the above hypothesis will require additional experiments: in particular, a single AGCM could be integrated after modifying the parameters that affect water vapor/lapse rate and/or cloud processes to produce enhanced feedback (or forcing) effects. As mentioned, atmosphere-only models are not explicitly "tuned" to match the observed surface temperatures, which are to first order dictated by the historical changes in SSTs. By analyzing the differences in model responses to changing SSTs and atmospheric chemical constituents, as conditioned on changes in relevant parameters, it will be possible to determine whether the above hypothesis is valid. Alternatively, similar experiments could be performed using a single coupled-climate model with modified longwave feedback parameters, but in that case the total radiative forcing from the model would have to be re-derived using the method of Forster and Taylor (2006).

Finally we note that the above hypothesis only holds for feedback processes that affect the longwave component of the global radiation budget. While there also appears to be an inverse relation between feedback and radiative forcing processes that affect the shortwave component of the global radiation budget (Kiehl 2007), it is expected that this inverse relation will weaken or disappear with a reduction of anthropogenic aerosol forcing (Kiehl 2007; Knutti 2008). In that case, model differences in the shortwaverelated feedback processes, which would no longer be offset by compensating changes in shortwave radiative 
forcing, could give rise to model differences in the overall equilibrium temperature response to enhanced GHG forcing. This may help explain why many model studies find that differences in model responses to enhanced greenhouse gas concentrations appear most sensitive to feedbacks involving changes in shortwave radiation (Bony and Dufresne 2005; Web et al. 2006; Ringer et al. 2006; Williams and Tselioudis 2007), as well as why there are still differences in equilibrium temperature responses in the coupled-climate models analyzed here (as seen in Figs. 8, 9).

\section{Conclusions}

Understanding the historical and future sensitivity of the global climate system to anthropogenic emissions of heattrapping gases and aerosols has become a timely and compelling concern. Presently, uncertainties in the magnitude of the historical climate response to anthropogenic emissions arise because of uncertainties in the strength of the feedbacks that subsequently modify this forcing, and hence in the sensitivity of the climate system to this forcing. In addition, some of the heat trapped by these emissions has been absorbed by the ocean, leading to uncertainties in their effective forcing of the climate. Finally, there exist uncertainties in the total radiative forcing itself associated with the increased concentrations of greenhouse gases and aerosols. Here we propose a methodology utilizing atmosphere-only general circulation models to estimate the historical radiative forcing arising from increased emissions of radiatively active atmospheric constituents, as well as the ocean-heat uptake associated with this radiative forcing and the expected climate change. This methodology is a modification of the Cess et al. (1990) climate-sensitivity studies and involves different AGCMs forced with observed changes in global-scale SST anomalies, and then forced with both global-scale SSTs and radiatively active atmospheric constituents.

Based upon TOA radiative fluxes from these two sets of simulations, we find that while the different modeling systems produce approximately the same historical global surface temperature response $(\sim 0.4 \mathrm{~K}$ over the period 1950-2000), their estimates of the total radiative forcing associated with the changing chemical composition of the atmosphere differ by a factor of two-thirds (from approximately $1.00-1.67 \mathrm{~W} \mathrm{~m}^{-2}$ ). In addition results suggest a range of global climate sensitivities in response to this forcing, from approximately $0.3-0.7 \mathrm{~K} /\left(\mathrm{W} \mathrm{m}^{-2}\right)$. However, the model estimates' of global climate sensitivities and total radiative forcing are not independent from one another but vary in a quasi-inverse way such that models with higher global climate sensitivities have lower total radiative forcings. Because of this inverse relationship, the model estimates of total expected surface temperature changes (compared with the mid-1950s) are similar across models (approximately $0.15 \mathrm{~K}$ difference between models), and show a much smaller range than if the total radiative forcing in each model is assumed to be the same (approximately $0.55 \mathrm{~K}$ difference).

Initial results from coupled ocean-atmosphere models, forced by $1 \%$ /year increases in $\mathrm{CO}_{2}$ concentrations, also indicate large inter-model differences in estimates of total radiative forcing and climate sensitivity. However, in agreement with the atmosphere-only general circulation models, results also suggest that certain models may have similar relationships between the total radiative forcing and climate sensitivity. For these models, the range of equilibrium temperature responses to future emissions of radiatively active chemical constituents is again less than if the full range of climate sensitivities, applied to a constant total radiative forcing estimate, is assumed.

It is important to note that in many current numerical model forecasts, the apparent offset between total radiative forcing and climate sensitivity may be accounted for if the model uses some form of radiative transfer code (e.g. Collins et al. 2006). However, it may not be accounted for in many probability studies, which treat the radiative forcing term as a fixed function of the GHG concentrations and then combine it with a range of sensitivities as determined from short-term or long-term observational products (Annan and Hargreaves 2006), or intermediate-complexity (Hegerl 2006; Knutti and Tomassini 2008) and fully coupled numerical model simulations (Murphy et al. 2004). Such an approach assumes that the radiative forcing is independent of all feedback processes; our results show that this may not be the case and that the temperature change may be more constant than is derived from such calculations.

Acknowledgments Dr. Anderson's research was supported by a Visiting Scientist appointment to the Grantham Institute for Climate Change, administered by Imperial College of Science, Technology, and Medicine.

\section{References}

Annan JD, Hargreaves JC (2006) Using multiple observationally based constraints to estimate climate sensitivity. Geophys Res Lett 33. doi:10.1029/2006GL06704

Bony S, Dufresne J-L (2005) Marine boundary layer clouds at the heart of tropical cloud feedback uncertainties in climate models. Geophys Res Lett 32. doi:10.1029/2005GL023851

Bony $\mathrm{S}$ et al (2006) How well do we understand and evaluate climate change feedback processes? J Clim 19:3445-3482

Boucher O et al (1998) Intercomparison of models representing direct shortwave radiative forcing by sulfate aerosols. J Geophys Res 103:16979-16998 
Brindley HE, Allan RP (2003) Simulations of the effects of interannual and decadal variability on the clear-sky outgoing long-wave radiation spectrum. Q J R Meteorol Soc 129:29712988

Brohan P, Kennedy JJ, Haris I, Tett SFB, Jones PD (2006) Uncertainty estimates in regional and global observed temperature changes: a new dataset from 1850. J Geophys Res 111:D12106. doi:10.1029/2005JD006548

Cess RD et al (1990) Intercomparison and interpretation of climate feedback processes in 19 atmospheric general circulation models. J Geophys Res 95:16601-16615

Collins WD et al (2006) The formulation and atmospheric simulation of the Community Atmosphere Model version 3 (CAM3). J Clim 19:2144-2161

Collins M et al (2007) The sensitivity of the rate of transient climate change to ocean physics perturbations. J Clim 20:2315-2320

Compo GP, Sardeshmukh PD (2009) Oceanic influences on recent continental warming. Clim Dyn 32:333-342

Dufresne JL, Bony S (2008) An assessment of the primary sources of spread of global warming estimates from coupled atmosphereocean models. J Clim 19:5135-5144

Edwards TL, Crucifix M, Harrison SP (2007) Using the past to constrain the future: how the paleorecord can improve estimates of global warming. Prog Phys Geogr 31:481-500

Folland CK, Sexton MH, Karoly DJ, Johnson CE, Rowel DP, Parker DE (1998) Influences of anthropogenic and oceanic forcing on recent climate change. Geophys Res Lett 25:353-356

Forest CE et al (2002) Quantifying uncertainties in climate system properties with the use of recent climate observations. Science 295:113-117

Forster PMF, Taylor KE (2006) Climate forcings and climate sensitivities diagnosed from coupled climate model integrations. J Clim 19:6181-6194

Frame DJ et al (2005) Constraining climate forecasts: the role of prior assumptions. Geophys Res Lett 32. doi:10.1029/2005GL09702

Gong X, Richman MB (1995) On the application of cluster analysis to growing season precipitation data in North America east of the Rockies. J Clim 8:897-931

Goody R, Haskins R, Abdou W, Chen L (1996) Detection of climate forcing using emission spectra. Earth Observ Remote Sens 13:713-727

Gregory J, Webb M (2008) Tropospheric adjustment induces a cloud component in $\mathrm{CO}_{2}$ forcing. J Clim 21:58-71

Hansen J et al (2002) Climate forcings in Goddard Institute for Space Studies SI2000 simulations. J Geophys Res 107. doi:10.1029/ 2001JD001143

Hansen J et al (2005) Earth's energy imbalance: confirmation and implications. Science 308:1431-1435

Harries JE, Brindley HE, Sagoo PJ, Bantges RJ (2001) Increases in greenhouse forcing inferred from the outgoing longwave radiation spectra of the Earth in 1970 and 1977. Nature 410:355-357

Hegerl GC (2006) Climate sensitivity constrained by temperature reconstructions over the past seven centuries. Nature 440:10291032

IPCC (2007) Climate CHANGE 2007: the physical science basis. In: Solomon SD, Qin M, Manning Z, Chen M, Marquis KB (eds) Contribution of working group I to the fourth assessment report of the intergovernmental panel on climate change

Jones PD, New M, Parker DE, Martin S, Rigor IG (1999) Surface air temperature and its variations over the last 150 years. Rev Geophys 37:173-199

Kiehl JT (1983) Satellite detection of effects due to increased atmospheric carbon dioxide. Science 222:504-506

Kiehl JT (2007) Twentieth century climate model response and climate sensitivity. Geophys Res Lett 34. doi:10.1029/2007GL031383
Knutti R (2008) Why are climate models reproducing the observed global surface warming so well? Geophys Res Lett 35. doi: 10.1029/2008GL034932

Knutti R, Tomassini L (2008) Constraints on the transient climate response from observed global temperature and ocean heat uptake. Geophys Res Lett 35. doi:10.1029/2007GL032904

Knutti R, Stocker TF, Joos F, Plattner G-K (2002) Constraints on radiative forcing and future climate change from observations and climate model ensembles. Nature 416:719-723

Knutti R, Krahenmann S, Frame DJ, Allen MR (2008) Comment on "Heat capacity, time constant, and sensitivity of Earth's climate system" by SE Schwartz. J Geophys Res 113. doi:10.1029/2007 JD009473

Levitus S, Antonov JI, Boyer TP, Garcia HE, Locarnini RA (2005) EOF analysis of upper ocean heat content, 1956-2003. Geophys Res Lett 32. doi:10.1029/2005GL023606

Lohmann U, Quaas J, Kinee S, Feichter J (2007) Different approaches for constraining global climate models of the anthropogenic indirect aerosol effect. Bull Am Meteorol Soc 88:243

Mitchell JFB, Wilson CA, Cunnington WM (1987) On $\mathrm{CO}_{2}$ climate sensitivity and model dependence of results. Q J R Meteorol Soc 113:293-322

Murphy JM et al (2004) Quantification of modeling uncertainties in a large ensemble of climate change simulations. Nature 430:768772

Penner JE et al (1994) Quantifying and minimizing uncertainty of climate forcing by anthropogenic aerosols. Bull Am Meteorol Soc 75:375-400

Pope VD, Gallani ML, Rowntree PR, Stratton RA (2000) The impact of new physical parametrizations in the Hadley Centre climate model-HadAM3. Clim Dyn 16:123-146

Quaas J, Boucher O, Lohmann U (2006) Constraining the total aerosol indirect effect in the LMDZ and ECHAM4 GCMs using MODIS satellite data. Atmos Chem Phys 6:947-955

Ramanathan V, Carmichael G (2008) Global and regional climate changes due to black carbon. Nat Geosci 1:221-227

Ringer MA et al (2006) Global mean cloud feedbacks in idealized climate change experiments. Geophys Res Lett 33. doi: 10.1029/2005GL025370

Robock A (2000) Volcanic eruptions and climate. Rev Geophys 38:191-219

Roe GH, Baker MB (2007) Why is climate sensitivity so unpredictable. Science 318:629-632

Roeckner E et al (1996) The atmospheric general circulation Model ECHAM4: model description and simulation of present-day climate. Max Planck Institut fur Meteorologie, Report no. 218, Hamburg, p 86

Sanderson BM, Piani C, Ingram WJ, Stone DA, Allen MR (2008) Towards constraining climate sensitivity by linear analysis of feedback patterns in thousands of perturbed-physics GCM simulations. Clim Dyn 30:175-190

Schwartz SE (2004) Uncertainty requirements in radiative forcing of climate change. J Air Waste Manage Assoc 54:1351-1359

Schwartz SE (2007) Heat capacity, time constant, and sensitivity of Earth's climate system. J Geophys Res 112. doi:10.1029/2007 JD008746

Sexton DMH, Rowell DP, Folland CK, Karoly DJ (2001) Detection of anthropogenic climate change using an atmospheric GCM. Clim Dyn 17:669-685

Shine KP, Cook J, Highwood EJ, Joshi MM (2003) An alternative to radiative forcing for estimating the relative importance of climate change mechanisms. Geophys Res Lett 30. doi:10.1029/ 2003GL018141

Soden BJ, Held IM (2006) An assessment of climate feedbacks in coupled ocean-atmosphere models. J Clim 19:3354-3360 
Sokolov AP, Forest CE, Stone PH (2003) Comparing oceanic heat uptake in AOGCM transient climate change experiments. J Clim 16:1573-1582

Stott PA, Kettleborough JA (2002) Origins and estimates of uncertainty in predictions of twenty-first century temperature rise. Nature 416:723-726

Trenberth KE, Stepaniak DP, Caron JM (2002) Interannual variations in the atmospheric heat budget. J Geophys Res 107. doi: 10.1029/20000JD000297

Web MJ et al (2006) On the contribution of local feedback mechanisms to the range of climate sensitivity in two GCM ensembles. Clim Dyn 27:17-38
Wigley TML, Ammann CM, Santer BD, Raper SCB (2005) Effect of climate sensitivity on the response to volcanic forcing. J Geophys Res 110. doi:10.1029/20050JD09107

Williams KD, Tselioudis G (2007) GCM intercomparison of global cloud regimes: present-day evaluation and climate change response. Clim Dyn 29:231-250

Wong $\mathrm{T}$ et al (2006) Re-examination of the observed decadal variability of earth radiation budget using altitude-corrected ERBE/ERBS nonscanner WFOV data. J Clim 19:4028-4040

Zeng N, Qian H, Munoz E, Iacono R (2004) How strong is carbon cycle-climate feedback under global warming? Geophys Res Lett 31:L20203. doi:10.1029/2004GL020904 